\title{
Benchmarking Reference Data Collection: The Results of a National Survey on Reference Transaction Instruments with Recommendations for Effective Practice
}

\author{
Rebecca Eve Graff \\ Southern Methodist University, USA
}

Paula R. Dempsey

University of Illinois at Chicago, USA

\author{
Adele Dobry \\ California State University, Los Angeles, USA
}

\section{Introduction}

This paper reports the results of a 2016 national survey on how reference data are collected and used, conducted by the Evaluation of Reference and User Services (ERUS) Committee, of the Reference Services Section, of the Reference \& User Services Association division of the American Librarian Association. Results include how academic libraries capture reference transactions and the extent to which the recorded data conforms to official definitions. We identify standard practices, recognize innovations, and offer recommendations. From our findings, readers will discover trends, opportunities, and tools for better documenting the value of reference services.

\section{Why is it important to learn how reference data are collected and used?}

Reference services in academic libraries are in transition. Negotiating multiple challenges requires evidence to guide decision-making. Therefore, it is important for those responsible for sustaining and improving reference service to understand how colleagues across the country gather and organize such evidence. Ideally, data about reference services will allow for cross-institutional studies. That is, academic libraries need a snapshot of current practices to inform the profession of where we were, where we are, and where we are going.

There has not been a national examination of how reference data are collected since the Association of Research Libraries (ARL) published a SPEC Kit on practices among its members in 2002. ${ }^{1}$ That study was precipitated by a "sharp reduction in the number of transactions recorded." At that time, nearly all academic libraries marked reference transactions with tick marks and about half of academic libraries collected transaction data only during sample periods. Now, according to our survey, fewer than $10 \%$ of academic libraries record transactions manually and $94 \%$ collect data at all times. The SPEC Kit sampled only ARL libraries and had a $62 \%$ response rate $(n=77)$. The current study had 142 responses from academic libraries of all types. Response rate cannot be calculated because there is no way to know how many institutions the invitation reached. Table 1 compares the two studies.

Table 1. Comparing SPEC Kit 268 and current study

\begin{tabular}{|l|l|l|}
\hline & SPEC Kit 268 (2002) & ERUS Survey (2016) \\
\hline Population/sample & $\begin{array}{l}\text { ARL members (n=124); 77 } \\
\text { responses (62\%) }\end{array}$ & $\begin{array}{l}\text { Email recruiting; 142 responses } \\
\text { from academic libraries }\end{array}$ \\
\hline Libraries collecting data & $96 \%$ & $95 \%$ \\
\hline Regular collection & $51 \%$ & $99 \%$ \\
\hline
\end{tabular}




\begin{tabular}{|c|c|c|}
\hline & SPEC Kit 268 (2002) & ERUS Survey (2016) \\
\hline Method of collection & $\begin{array}{l}\text { (Select all that apply) } \\
99 \% \text { hand tabulated } \\
25 \% \text { online data entry } \\
4 \% \text { clicker } \\
8 \% \text { other }\end{array}$ & $\begin{array}{l}75 \% \text { commercial platform } \\
6 \% \text { hand tabulated } \\
8 \% \text { online spreadsheet } \\
11 \% \text { other (freeware, clicker, in- } \\
\text { house database) }\end{array}$ \\
\hline
\end{tabular}

Academic librarianship has experienced a "refolution" in the last 25 years, from the card catalog to the online catalog to the catalog to discovery layers. We transitioned from print indexes to CD-ROMs to the information superhighway to online databases. We went from using indexes and tables of contents to Boolean searching using facets and limiters; bibliographic instruction to information literacy; and from identifying sources to developing search strategies. At the reference desk, we used to answer a lot of questions, mostly basic ones about how to use the library. We taught patrons how to start with the Encyclopedia Britannica and the Readers' Guide to Periodical Literature to identify a few related resources. Now, we get fewer, more complicated questions, which require our professional expertise. Librarians are needed to help identify the most relevant sources and retrieve the full text. ${ }^{2} \mathrm{We}$ went from a designated reference desk to a variety of options for providing research encounters, and from personal interactions to asynchronous research help. ${ }^{3}$ Most pertinent to this discussion, we moved or are moving from tally marks to online forms, allowing detailed information to be gathered at multiple service points and from individual work spaces. ${ }^{4}$

\section{Why is it important to capture and analyze reference data?}

Ask yourself why you keep reference statistics. In addition to the data that is required by administrators, professional associations, and accrediting bodies, the information we collect should help us understand how best we can assist our patrons, in terms of both staffing and training. It should be used to demonstrate to our stakeholders how much value we provide our communities and open the door to programmatic evaluation. However, research, guidance, and professional discussion about how to collect meaningful evidence on reference practice are limited. ${ }^{5}$ The excellent report on The Value of Academic Libraries included only two paragraphs specifically on reference services. ${ }^{6}$ In the literature review of the article, it discusses how librarians can improve graduation rates through one-on-one interactions with students through "individualized research assistance and personal attention." ${ }^{7}$ Professional organizations currently lack a forum for academic reference librarians to have in-depth conversations about tracking and measuring the value of reference interactions.

Our results contribute to a culture of data-driven decision-making and fill a gap in the literature. With good reason, the overwhelming majority of libraries focus solely on quantitative data. To complement that information, we will suggest qualitative measures that further demonstrate the value of professional librarians to stakeholders. For example, we will explore how librarians can document use of the Framework for Information Literacy for Higher Education to enhance research interactions and bolster our teaching profile on campus. $^{8}$

\section{What did we want to learn from our survey?}

Have libraries taken advantage of the opportunities provided by online transaction recording methods? Is there consistency among libraries? Are forms designed to capture the value added by interacting with a trained librarian or to capture the impact of reference interactions on patrons' learning outcomes? What are best practices for academic libraries? 


\section{Methods}

To find answers, the ERUS committee created a survey using Qualtrics, including basic demographic information, such as library type (figure 1). Then, our team requested participation through library-related Listservs (brass-l, libref-l, medref, pla, pla-eval, rss-eforum, rss-l, rusavr) and Facebook sites (ALA, RUSA, ALA Think Tank). By using a variety of posting forums, we sought to ensure participation from across the profession. We requested that librarians upload the forms they use for capturing reference interaction information (see figures 1 and 2 for sample screen shots). We also inquired about changes libraries have made regarding what data they collect, and we asked respondents to indicate the most useful statistics gathered (see figure 3). See appendix for the survey instrument.

\section{Figure 1. Sample screen shot (complex form)}

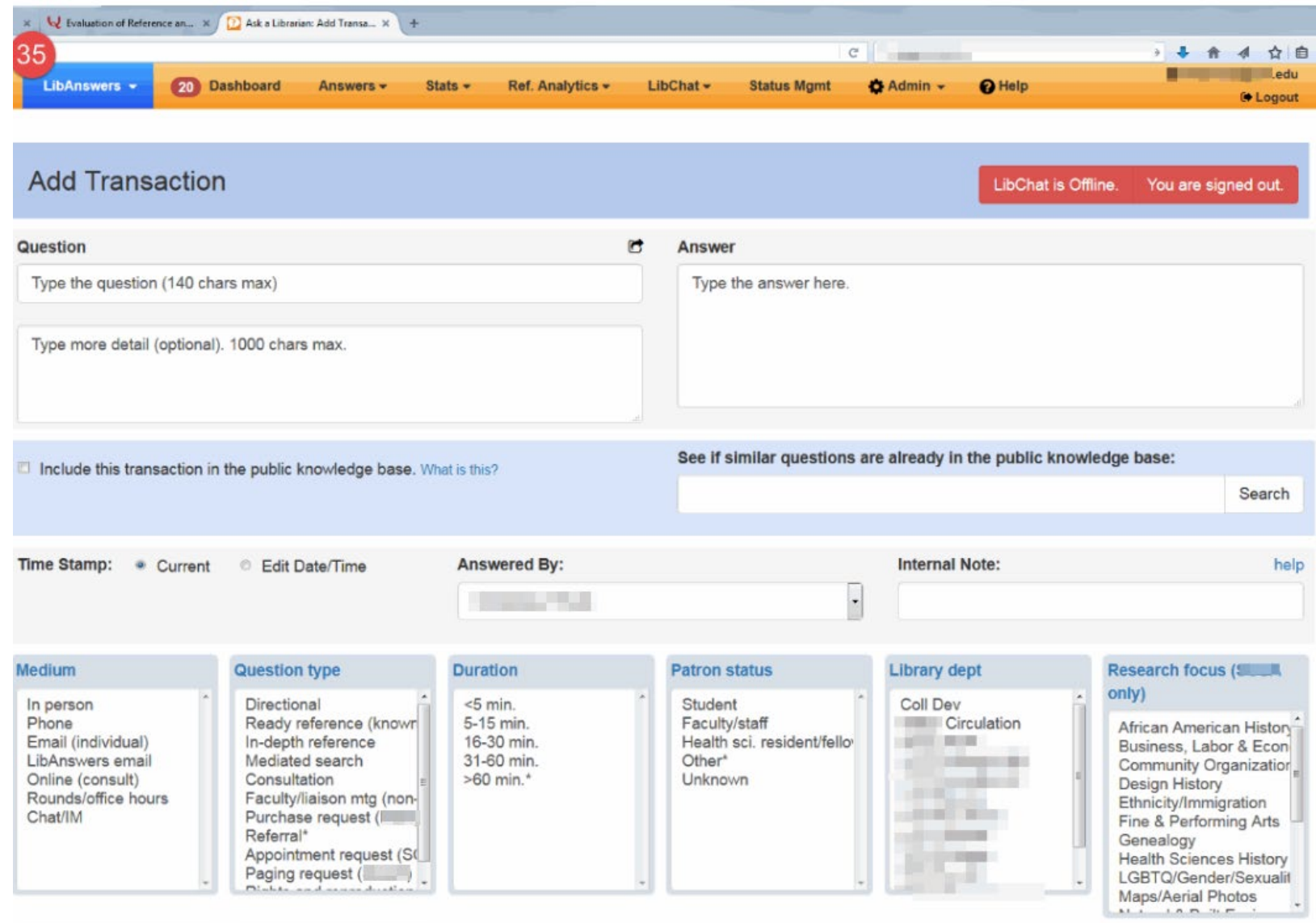


Figure 2. Sample screen shot (streamlined form)

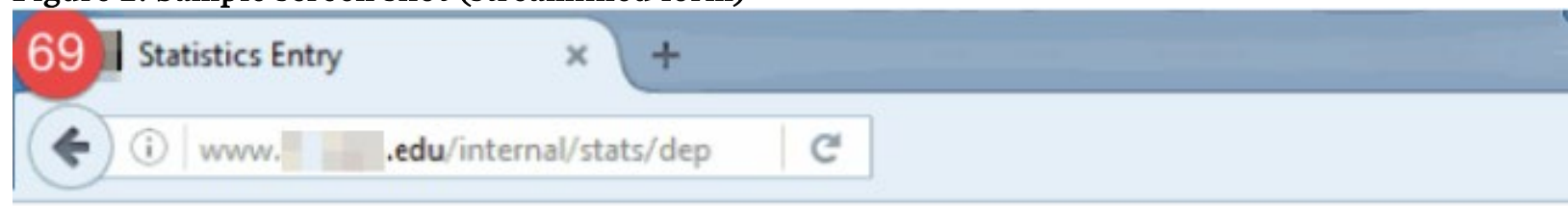

Reference Stats I Return to Loqin I What is a Reference Question? I READ Scale Info,

You have successfully added your reference statistic.

\section{Library Reference Desk}

Today's Question Count: Directional: 3 Reference: 2 Technical: $\mathbf{1}$ I view by hour

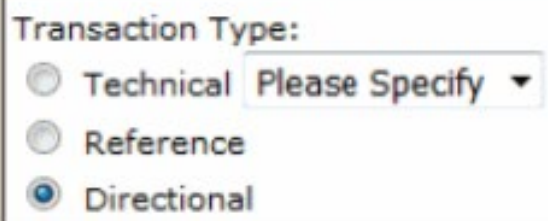

Time of transaction:

- Current time Modified (24hr format)

Time Spent [optional - in minutes "10"]:

1

If you leave the desk, mark a reason:

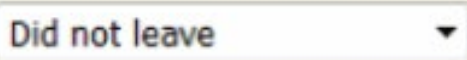

Communication Method:

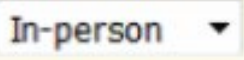

Your Name [optional] :

Note [optional]:

\section{Results}

We received 232 responses, primarily from academic (61\%) and public (31\%) libraries. This paper focuses on data from the 142 academic libraries. We analyzed the data in two ways: (1) self-reported responses to our questions and (2) the transaction forms submitted, of which there were 62 usable samples. We learned that just over $94 \%$ of academic libraries that responded collect data on reference interactions at all times, $5 \%$ collect data during sample periods, and less than $1 \%$ do not collect reference data. 
Before evaluating the reference-transaction forms, we anonymized the submissions, removing institutional information and assigning numeric identifiers. Of the academic libraries that responded to a question about data capture method, the most common was a commercial app $(n=40)$, followed by freeware $(n=18)$, and a printed sheet $(n=4)$. The most common commercial solution used was SpringShare RefAnalytics $(n=28)$ (see figure 1), followed by Gimlet ( $\mathrm{n}=10)$ and Desk Tracker $(\mathrm{n}=2)$. Among libraries using a free solution, 14 could not be identified (see figure 2); three used Zoho Creator, and one used Google Forms.

Most libraries (72\%) reported that they had changed their data gathering approach in the past 10 years. Figure 3 shows the reasons libraries gave for changing their approach. Qualitative analysis of the comments provided show a distinction between what has changed in libraries' approach and the reasons for the changes.

Figure 3. Reasons libraries reported for making changes in transaction data

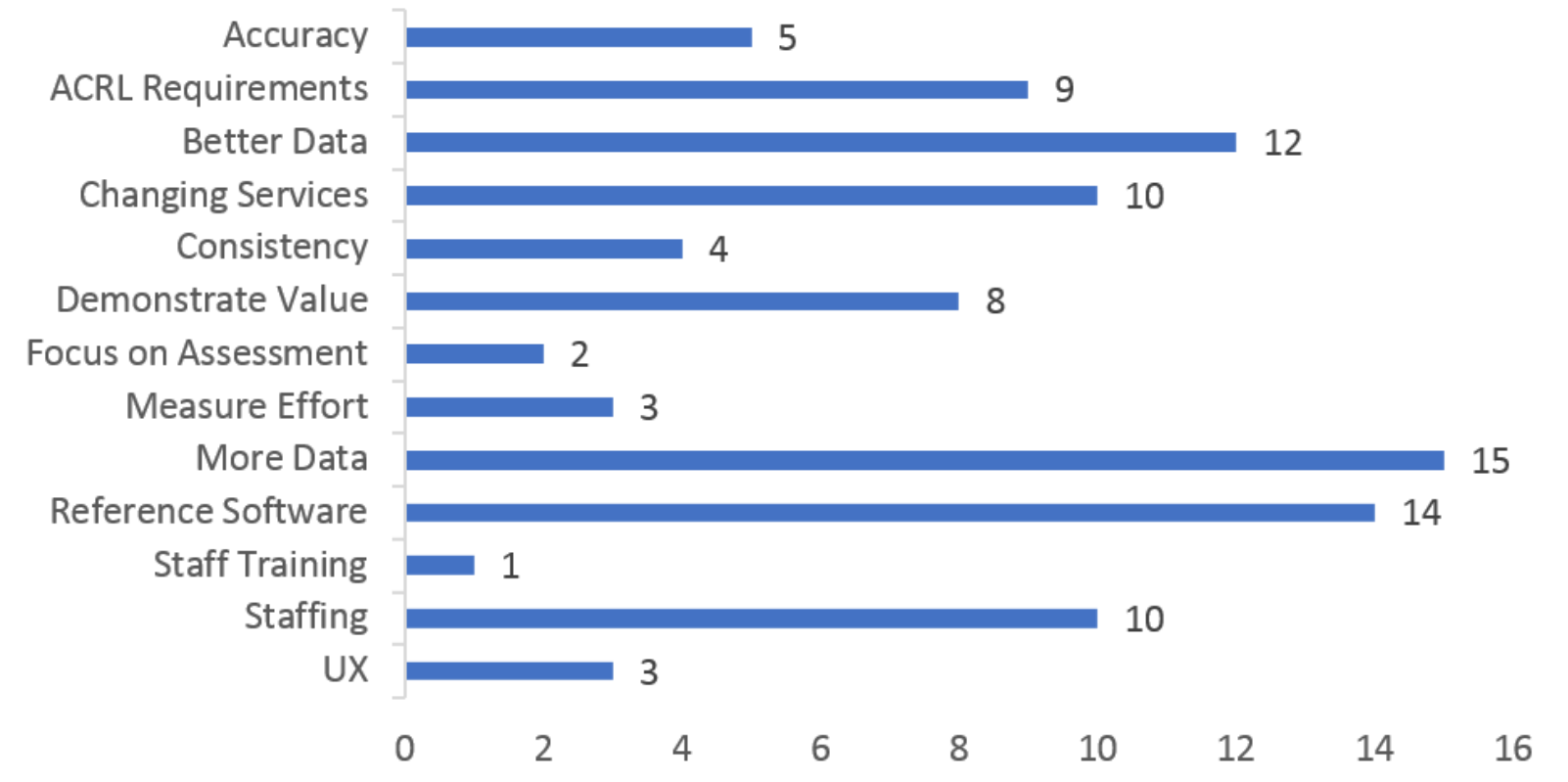

Libraries reported the following changes in the data collected:

- Better definitions

- Different categories

- More detail

- New location or service

- Started collecting data

- Paper to online

- New online system

- Sample to continuous collection

Motivations for these changes included the following:

- Accuracy/consistency

- Accreditation standards/external reporting

- Change in institution (e.g., corporate culture, merger, staffing model)

- Assessment/documenting impact or value

- Needs analysis, monitoring change

- Equipment 
- Service improvement/training

- $\quad$ Staffing levels

Examination of the 62 forms submitted showed that most did not clearly distinguish reference questions from other kinds of inquiries. Libraries used an inconsistent multitude of categories, as depicted in figure 4 . "Directional" was the most common question type, followed by "Reference." For the most part, there was no clear distinction between reference questions and other types of inquiries without post-sorting data. Forms did not appear to conform to the RUSA or ARL definitions of reference, but a few forms linked to a definition. ${ }^{9}$ The study did not examine instructions for service providers, which might have provided the definition. Rather, forms included a range of question types that fall into the definition of reference, such as "ready reference," "brief reference," "extended reference," and "in-depth reference."

\section{Figure 4. Word cloud of question types used in 62 sample forms}

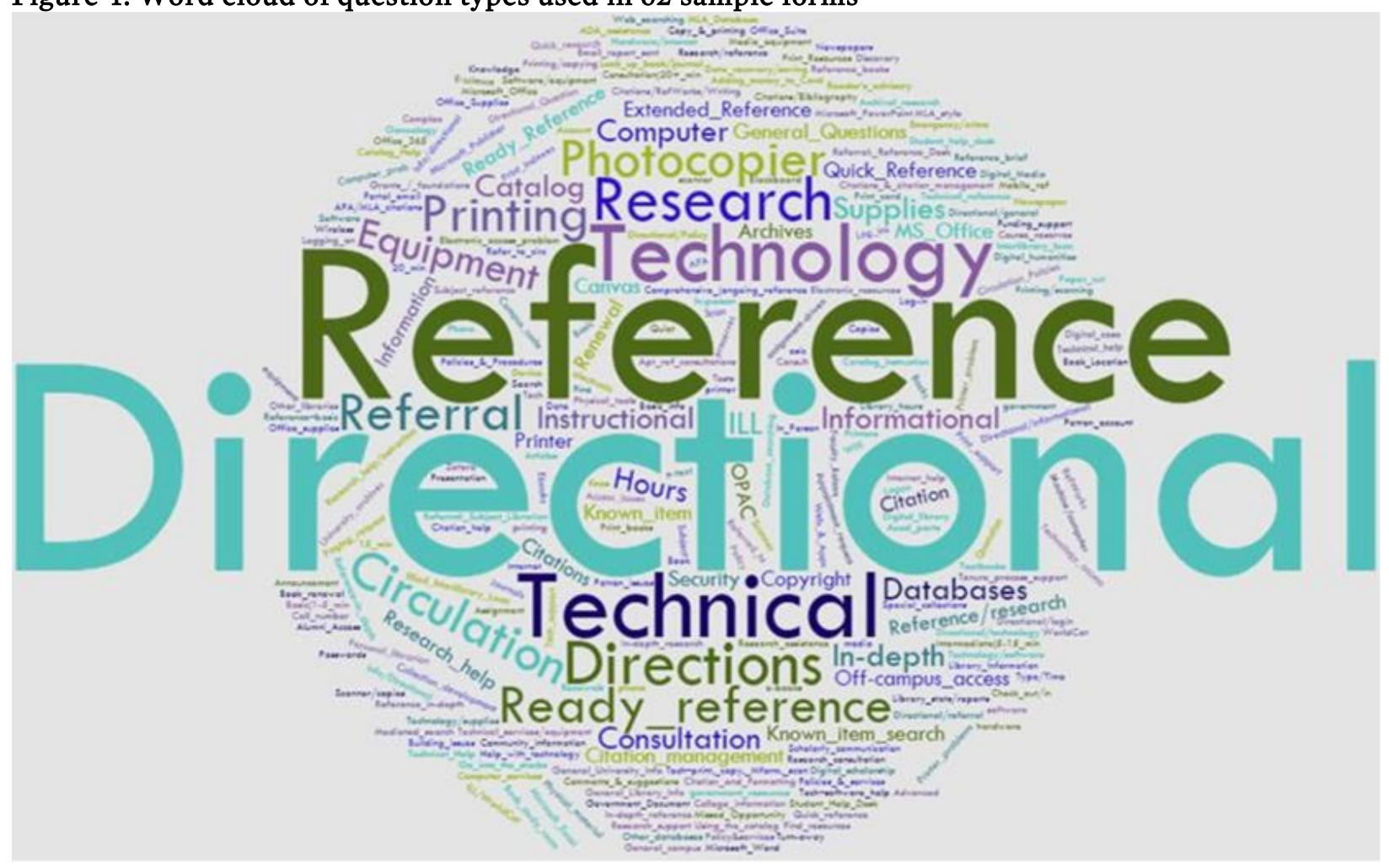

These options would require more complicated processing of data to extract the data to respond to Association of College \& Research Libraries (ACRL) surveys and other external stakeholders. Given that most forms also included a duration field, it is not clear why the forms separate brief from in-depth questions. However, the value options provided under duration varied wildly in their precision, and some forms conflated the length of interaction with its difficulty. For example, some forms provided two options, 0-5 minutes and 5+ minutes, while others were more granular in options. The large proportion of forms that used text entry fields rather than a drop-down list for data points such as library departments further complicated data analysis.

Of the 62 forms analyzed, 7 were labeled for use at one specific service point and 55 gathered data from a range of service points such as "Circulation," "Consolidated Service Desk," "Office," "Roving," or "Embedded Classes." The unique circumstances of providing services in these locations might have complicated design of the forms. Most forms ( $n=57)$ also noted contact mode: in person, phone, email, chat, SMS/text, etc. Three forms did not collect contact format, and two forms were unclear. 
As noted, most reference data gathered by respondents were quantitative, counting interactions and/or documenting their duration (55\%). As the ARL definition stipulates, duration is not an appropriate indicator of whether an interaction is a reference question. Nor is it necessarily a signal of quality service. An experienced librarian might take minutes to find information that a novice will take much longer to locate. How staff spend their time is not the same as whether they are using time effectively or are in need of professional development.

The most common qualitative measure was the READ (Reference Effort Assessment Data) Scale. ${ }^{10}$ It is reasonable to wonder how fully the measure is understood, as well as whether staff apply it consistently. Do librarians follow the guidelines for recording responses or do they treat it as an indicator of personal effort. Like duration, the READ Scale might be affected by individual experience and skill-was the inquiry one that would be simple for a subject matter expert and difficult for a novice? Moreover, most of the examples given for levels one and two do not merit inclusion as reference inquiries, based on organizational definitions. ${ }^{11}$

Another common qualitative category was to classify patrons by status or affiliation $(n=28)$. For most ondemand interactions, unlike appointments or embedded services, it is unlikely to be clear whether someone is an undergraduate student, graduate student, staff member, professor, or person unaffiliated with the institution. Thus, these data might consist largely of guesses or missing data.

Only a few respondents used a form designed to capture the value added by interacting with a trained librarian or how the interaction may have influenced a patron's learning outcomes. One attempt to gather this qualitative measure: "Was their actual information need different from their original question?" This measure appears to get at the need for an effective reference interview to ascertain the patron's underlying research need. ${ }^{12}$ However, staff members who neglect to conduct an effective reference interaction would not be able to answer the question correctly. Another example: "Did you do follow-up work on this question off-desk?" How likely is it that a reference provider will go back into the system to modify their response?

\section{Discussion and Recommendations for Best Practice}

This study shows that nearly all academic libraries have left behind the paper tally sheet in favor of capturing reference statistics online. A major benefit of online data collection is that we can record all our reference interactions, regardless of where they occurred. This is important in a context where librarians provide services as liaisons or embedded librarians in locations beyond the desk and outside the library. Designing online data collection forms, whether a commercial format or homegrown system, requires thoughtful assessment of how the data will be analyzed and used. Two tensions can be inferred from the forms collected for this study: a tension between maximizing the details of local practice and streamlining the form, and a tension between locally informative data and cross-institutional consistency.

To find the sweet spot in these tensions, determine what you want to measure and use design thinking when creating your form. Start with the end in mind. What information are you required to collect? What is most important to you for longitudinal decision-making? If any of the information you are gathering is incidental to these kind of questions, you do not need to collect it. What is actionable, noteworthy, or required? Focus on documenting reference assistance and its impact on patrons rather than expecting the form to also guide collection development (which sources staff use or recommend most often), training priorities (which tools are used most often), or instruction design (what patrons do not know). If a form is supposed to do everything, can the form be useable (will people complete it) and data be truly useful?

To streamline the form, consider eliminating elements that will not contribute to decision-making and service improvement, rather than focusing on what is easy data to gather. For example, duration, mode of contact, and patron type are common fields that might not yield benefits that outweigh the time it takes to gather them. In terms of duration, how much time it takes to adequately help someone may be of use when explaining our value to administrators, but is it worthwhile documenting duration for each question?

Instead, the library could sample key weeks and station an observer to accurately measure the duration of interactions, rather than relying on guesses from busy service providers. Knowing how much time was spent 
giving assistance, as opposed to simply staffing, may be worth exploring, but guesstimating does not provide actionable data. In terms of contact mode, does it matter if a question came via the telephone or in person? Will you change staffing based on this? In terms of patron type, how often do people self-identify as an undergraduate student, graduate student, faculty member, etc.? That is, how often are these guesses for inperson questions? And, once again, would you change staffing based on this?

The software that frees us from the limitations of printed forms provides us with opportunities to reconsider what data to collect, corresponding to our various missions and priorities. Once you have determined which data are most important, strive for consistency:

- Link to definitions of categories and have regular refreshers in meetings about the meaning and importance of gathering such data accurately.

- Use drop-down lists to standardize data such as departments.

- Conduct periodic audits of data for set periods to look for spikes or drop-offs in question types for particular reference shifts that might indicate a need for further training.

Academic librarians seldom should supply answers. We have a pedagogical imperative to teach skills. Qualitative data helps to communicate what librarians do with students, how we help them learn, and how librarians enhance the research experience. ${ }^{13}$ We must demonstrate expertise and unpack the "black box" of the research interaction. To do so effectively, college and university librarians require more opportunities to discuss how to manage these challenges on a professional level with our institutional peers.

With the increase of research consultations and the integration of information literacy principles into reference interactions, it may be more useful to focus on collecting rich data about those interactions, especially given the level of resources expended in scheduling and preparing for individual meetings with patrons. The reference consultation can be an opportunity to demonstrate the extent to which librarians helped students across thresholds highlighted in the Framework. If expectations increase about documentation of research consultations, it might be wise to have librarians add 15 minutes to appointment periods to allow for note-taking. As we envision what ideal transaction forms might include in terms of value-added qualities, we might look to what Radford University has done when mapping instructional activities to aspects of the Framework and make similar connections to what happens in a research consultation. ${ }^{14}$

\section{Limitations and Future Research}

The design of the survey instrument led to more interpretation than is desirable. The study was also limited by the screenshots, which often used dropdown lists that only showed "select a value" rather than the complete list. The survey did not request instructions from staff about how to enter reference statistics. Such documentation might have clarified the definition of reference used.

\section{-Copyright 2019 Rebecca Eve Graff, Paula R. Dempsey, and Adele Dobry}

\section{Acknowledgements}

The authors gratefully acknowledge the contributions of the members of Evaluation of Reference and User Services (ERUS) Committee of the Reference Services Section of the Reference \& User Services Association division of the American Librarian Association: Ellen Keith, Lori Lauterbach, Jerilyn Marshall, Jenise Overmier, Jane Stephens, Fay Verburg, and Jeremy Walker.

\section{Notes}

1. Eric Novotny, SPEC Kit 268: Reference Service Statistics \& Assessment (Washington, DC: Association of Research Libraries, Office of Leadership and Management Services, 2002), https://www.arl.org/resources/spec-kit-268-reference-service-statistics-a-assessment-september-2002/. 
2. David A. Tyckoson, "Issues and Trends in the Management of Reference Services: A Historical Perspective,” Journal of Library Administration 52, no. 6-7 (2012): 581-600, https://doi.org/10.1080/01930826.2011.556936.

3. Sara Davidson and Susan Mikkelsen, "Desk Bound No More: Reference Services at a New Research University Library,” The Reference Librarian 50, no. 4 (2009): 346-355, https://doi.org/10.1080/02763870903143591.

4. Robert Flatley and Robert Bruce Jensen, "Implementation and Use of the Reference Analytics Module of LibAnswers," Journal of Electronic Resources Librarianship 24, no. 4 (2012): 310-315, https://doi.org/10.1080/1941126X.2012.732838; Christy R. Stevens, "Reference Reviewed and ReEnvisioned: Revamping Librarian and Desk-Centric Services with LibStARs and LibAnswers," The Journal of Academic Librarianship 39, no. 2 (2013): 202-214, https://doi.org/10.1016/j.acalib.2012.11.006.

5. Naomi Lederer and Louise Mort Feldmann, "Interactions: A Study of Office Reference Statistics," Evidence Based Library and Information Practice 7, no. 2 (2012), http://ejournals.library.ualberta.ca/index.php/EBLIP/article/view/12282/14076.

6. Association of College and Research Libraries, Value of Academic Libraries: A Comprehensive Research Review and Report, prepared by Megan Oakleaf (Chicago: Association of College and Research Libraries, 2010), http://www.ala.org/acrl/sites/ala.org.acrl/files/content/issues/value/val_report.pdf.

7. ACRL, Value of Academic Libraries.

8. Association of College \& Research Libraries, "Framework for Information Literacy for Higher Education," American Library Association, February 2, 2015, http://www.ala.org/acrl/standards/ilframework.

9. Reference and User Services Association, "Definitions of Reference," January 14, 2008, http://www.ala.org/rusa/guidelines/definitionsreference.

10. Bella Karr Gerlich and G. Lynn Berard, "Testing the Viability of the READ scale (Reference Effort Assessment Data)(C: Qualitative Statistics for Academic Reference Services," College \& Research Libraries 71, no. 2 (2010): 116-137, https://doi.org/10.5860/0710116.

11. Bella K. Gerlich, "READ Scale Bulleted Format,” The READ Scale (Reference Effort Assessment Data), http://readscale.org/read-scale.html.

12. Dave Harmeyer, The Reference Interview Today: Negotiating and Answering Questions Face to Face, on the Phone, and Virtually (Lanham, Md.: Rowman \& Littlefield, 2014).

13. Susan Avery and David Ward, "Reference Is My Classroom: Setting Instructional Goals for Academic Library Reference Services," Internet Reference Services Quarterly 15, no. 1 (2010): 35-51, https://doi.org/10.1080/10875300903530264.

14. Radford University, McConnell Library, "Instruction Menu," https://www.radford.edu/content/library/instruction/faculty-request-a-workshop/instructionmenu.html.

15. Reference \& User Services Association, "Guidelines for Behavioral Performance of Reference and Information Service Providers,” http://www.ala.org/rusa/resources/guidelines/guidelinesbehavioral. 
Appendix A. Survey Instrument

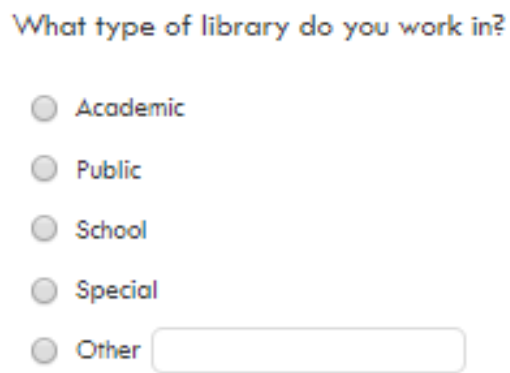

Does your library collect data on reference interactions?
Yes, at all times
Yes, for sample periods
No

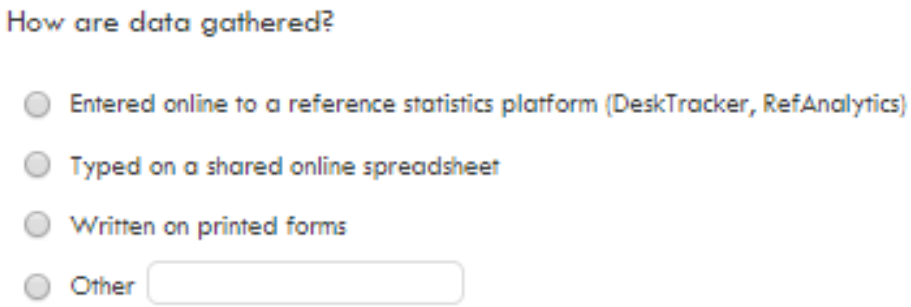

- Mac

- $\underline{\mathrm{PC}}$

Drop files or click here to upload

Why do you think these changes were made?

What is the most useful data you record? Why? How is it used? 
Appendix B. Example of an Easy-to-Use LibAnswers Service Transaction Form

This example merely serves as an example of how we might capture data differently; it has not been tested.

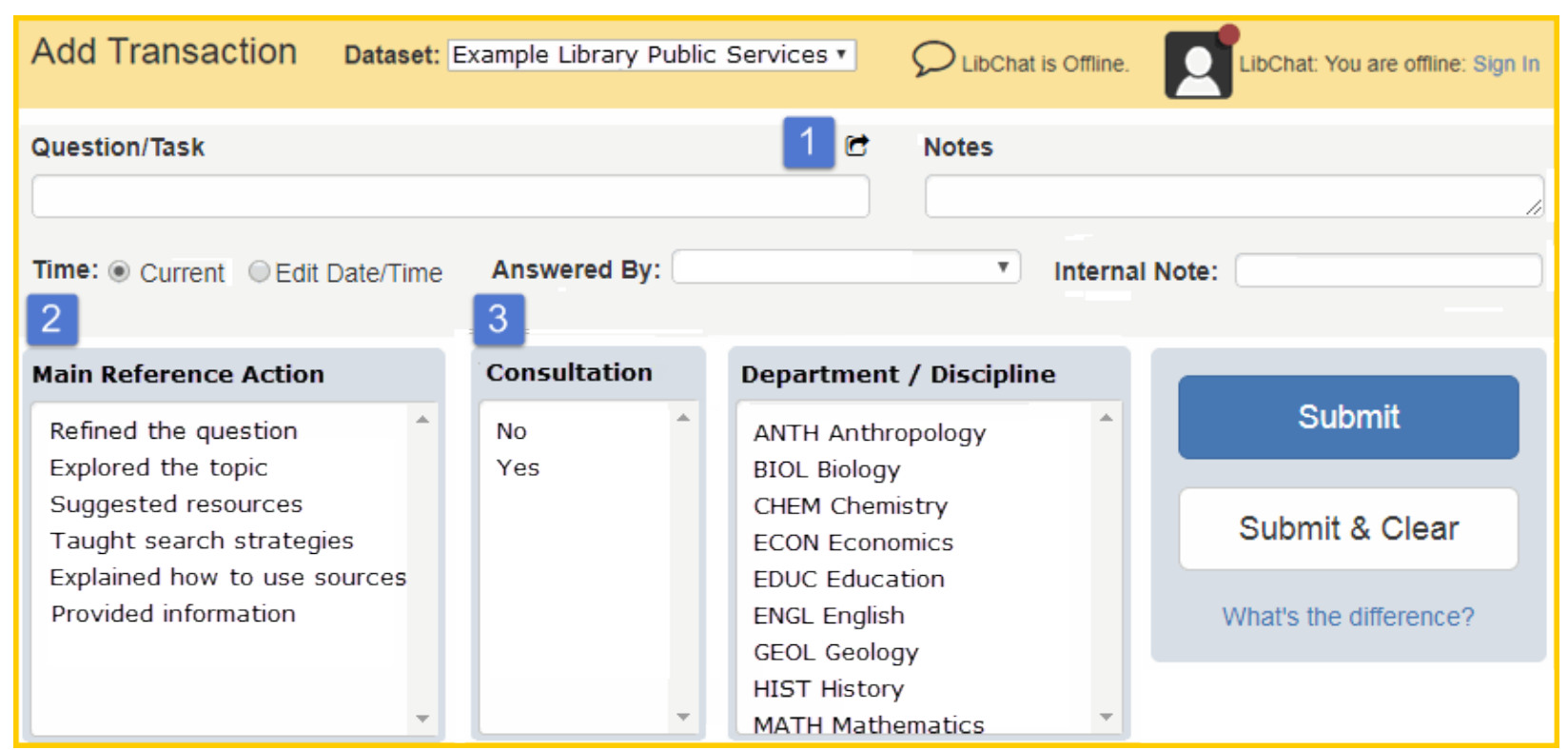

1. If it is not a reference question, select from the pre-defined entries, then Submit.

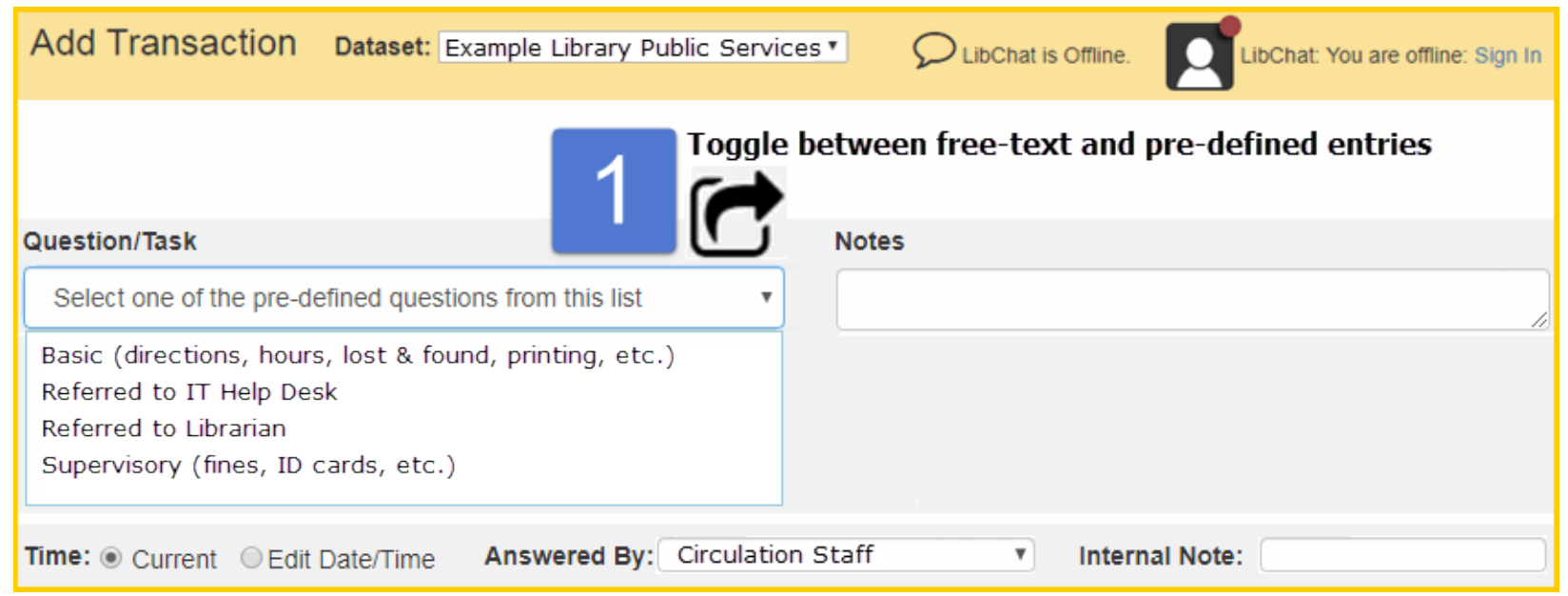

2. If it is an on-demand reference question, select a response based on Guidelines for Behavioral Performance of Reference and Information Service Providers, ${ }^{15}$ then Submit. 


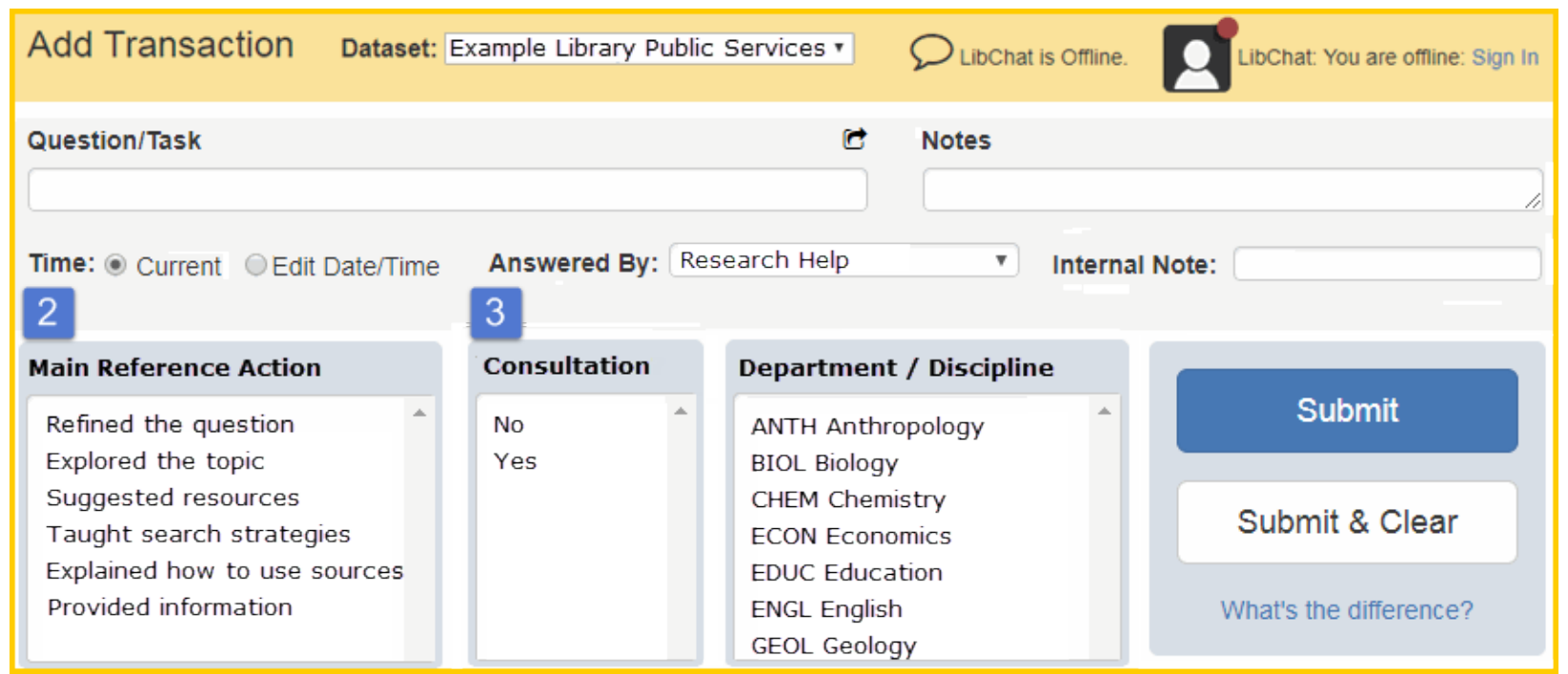

3. If it is a scheduled research consultation, indicate with Yes and select which department or discipline the person is from, then Submit. 